\title{
sciendo
}

$10.2478 / \mathrm{msd}-2018-0008$

\section{SUSTAINABLE DEVELOPMENT OF C.I. UNDER BRI -BASED ON THE C.I. AT LUCIAN BLAGA UNIVERSITY OF SIBIU}

\author{
Wang, JIONG \\ Beijing Language and Culture University, China, Email: wangjiong@blcu.edu.cn;
}

\begin{abstract}
The purpose of the research is to clarify what makes "sustainability" possible in Confucius Institute (C. I.) development when facing the challenging as well as opportunities in the international background, especially under the "Belt and Road Initiative" (BRI). It explores the strategies of ensuring the long-term possibility of achieving the goal of C.I. world widely, which is to teach Chinese language and to promote culture exchange between different cultures. The study concerns 3 dimensions of supportive elements: basically, management support of universities at home and abroad plays the essential role in the evolution of C.I.; furthermore, based on the links with the education section at different levels, expanding teaching branches brings stable and massive learners of Chinese language for C.I.; Finally, teaching quality control is the cornerstone of C.I. as an international exchange platform. Collectively, the research will be based on the analysis of C.I. at Lucian Blaga University of Sibiu in Romania to discuss the "sustainable development" under B\&R initiative. Based on literature review and comparative research, the study will first review the literature and the background of BRI. In the second part, support from the two sides of cooperation in building C.I. and strategies concerning the expansion of teaching branches of C.I. with the link between C.I. and different levels of education section will be discussed. In the third part, last but not the least, detailed research will be done on the teaching quality control. Therefore, we may finally assume that the sustainable development of C.I. can't be realized if any of the above condition is missed.
\end{abstract}

KEY WORDS: sustainable, C.I., training, local teachers, BRI,

\section{LITERATURE REVIEW AND BACKGROUND OF THE RESEARCH}

The first C.I. was built in Nov. 21, 2004 in Korea. In the past decade, people all over the world have shown enthusiasm to learning Chinese language and Chinese culture, and it continues heating up. Up till now, Confucius Institutes have come to a phase of extremely rapid development. Therefore, some mentioned that it is of great importance for C.I. to realize the sustainable development (Zhan, Ch.Y.\& Li, M.N. , 2014 ${ }^{1}$; Wang, 2011; Sun, 2012; Hu, Q.L. 2013) Zhan \& Li mentioned that we should gradually form a scientific and effective development model to motivate and guide its road to sustainable development. Problems and challenges have been

\footnotetext{
${ }^{1}$ It is necessary to set the first-level indicators and build a systematic sciencebased curriculum based on the six key elements of "thinking, operating, teaching, project, impact, reward and punishment".
}

also discussed (Wang, 2011) concerning lack of enough support in cooperation, incomplete curriculum with no unified teaching material with local characteristics, and short of teaching faculty, though solutions to the problems have not been clarified. When mentioning sustainability, people tend to think of environmental development ${ }^{2}$. As Blum (2012) is researching on environmental sustainability, theories and practices are quite alike. Here in the research, sustainability of interactions between different organizations and dimensions have been emphasized.

\footnotetext{
2 The discussion highlights the need for more research to understand the broader social and economic interactions between such efforts and the communities in which they are located. (Blum, 2012)
} 
Talking about C.I., we may find many researches about the sustainable development of education (Gough \& Scott, 2008 ${ }^{3}$; Nikolopoulou, 2010; Gadsby \& Bullivant 2011 ${ }^{4}$; Filho, 2011 ${ }^{5}$ ) Nikolopoulou (2010) provided multiple perspectives regarding the possibility of creating sustainable education practices that are integrated into and relevant to the needs and practices on a global scale ${ }^{6}$. Based on this idea, the research will be further done on the point that multiple perspectives concerning establishing workable links between universities, local communities, governments and teaching quality control would enable sustainable development of Confucius Institute, under the background of $B \& R$.

As C.I. of Sibiu locating in Romania, one of the important countries in the eastern Europe, we are facing challenges as well as opportunities under B\&R. With a long and complex history, Romania lying along the Belt and the Road, has its unique culture characteristics and is coming to a critical period in developing. As Ambassador Xu Feihong mentioned, the $\mathrm{B} \& \mathrm{R}$ is a way of learning from each other. We are in a world of multipolarization, economic globalization and cultural diversity. All countries are seeking peace and development. It requires $u s$ to strengthen communications and cooperation between different cultures along the Belt and Road, most of which are in a critical period of development and transformation. Therefore, it is imperative to introduce high technologies and learn experience from each other. The B\&R platform will "help countries along the line to strengthen communication and cooperation in development strategies, infrastructure construction, trade and investment facilitation and create a community of interests, fates and community of mutual trust, economic integration and cultural inclusion" $(\mathrm{Xu}$, 2015). With "cultural inclusion", cooperation and mutual understanding can be guaranteed. For the "cultural inclusion", C.I. of Romania have to maintain responsibility and sustainable development. To achieve this sole goal, C.I. needs the support from both China and the cooperative partner.

\footnotetext{
${ }^{3}$ It aims to raise both awareness and the standards of debate on the fundamental issues that lie at the very heart of higher education and intends to assist national and international debate. Higher education and sustainable development examines whether it is actually possible to mandate, plan, monitor and evaluate the higher education sector's route to the production of educated, innovative, independent, self-determining, critical individuals while at the same time achieving a range of wider policy goals on the side.

${ }^{4}$ It outlines the different ways in which global learning can be delivered as a cross-curricular theme, with examples of current activities and practice in schools.

5 It believes that sustainable development of education, though a particularly challenging task, is feasible and achievable, provided the right elements are put into place. It attempts to research on the documenting and disseminating experiences from different parts of the world.

${ }^{6}$ Focuses are also put on the failure of traditional education to address the problems of globalization.
}

\section{SUPPORT FROM THE TWO SIDES OF COOPERATION IN BUILDING C.I. AND EXPANSION OF TEACHING BRANCHES.}

The research here will not provide multiple perspectives regarding the possibility of creating sustainable practices for C.I. in Romania, which we believe there exist more elements integrated, we will focus in this research on the aspect concerning the relevant links between both sides of the partners co-building C.I. and it brings about the wide spread of the teaching branches in different cities, to the needs and practices on a national scale in Romania, like Sibiu C.I. with about 50 teaching branches in 12 cities in Romania.

\subsection{Links between universities: management support from LBUS and BLCU}

The research will be based on the practice of the Confucius Institute at Lucian Blaga University of Sibiu (LBUS), which is the first Confucius Institute in Romania, was co-founded with Beijing Language and Culture University in China(BLCU) and the Lucian Blaga University of Sibiu(LBUS) in 2007 and was awarded with the title of "Advanced Confucius Institute" in 2014. BLCU is known as being "Little United Nations" in China for having gathered students from every corner of the world, and widely recognized as the best university for teaching Chinese language to foreigners and training teachers of teaching Chinese as foreign language. Combined with the reputation of LBUS in Romania, C.I. of Sibiu have been expanding its fame immediately in Romania and attracting average of 4000 students every year interested in Chinese language and Chinese culture in the city of Sibiu and other 12 cities of Romania to register the Chinese language course.

As we all know that "sustainability is a dynamic concept" (Bossel, 1999) ${ }^{7}$, the links between the two sides are adaptable to the development of Sibiu C.I. Over the past ten years, the Confucius Institute of Sibiu (CIS) has been wholly dedicated to the development of Chinese language teaching and the promotion of Chinese culture. For this purpose, BLCU provides two departments headed directly by the vice-president of the university to manage the service for all-round need in terms of sending Chinese directors (3 Chinese directors), Chinese professors (18 Chinese teachers and professors) and volunteer teachers (42 volunteer teachers) to teach in CIS. President and

\footnotetext{
7 Societies and their environments change, technologies and culutres change, values and aspirations change, and a sustainable society must allow and sustain such change, i.e., it must allow continuous, viable and vigorous development, which is what we mean by sustainable development.
} 
vice-president of BLCU take part in significant moments of C.I. both in Romania and China, for example, vice-president Liu Wei leading a delegation joined the $10^{\text {th }}$ anniversary of CIS in November of 2017 in Sibiu, President Liu Li met the LBUS delegation in Xiaan in December of 2017, assistant-president Zhang Baojun attended the conference in March of 2018 in Constanta. At the same time, Rectors of LBUS getting involved in person in important issues and activities of CIS and later appointed the ex-Rector as the Romanian director for better connections with colleges and departments of LBUS, offering fully support for great achievement in the past years. A number of teaching sites have been established covering 13 cities in Romania - Constanta, Pitesti, Deva, Petrosani, Miercurea Ciuc and so on: and the number of students has reached about 4,000 by the year of 2017. The activities carried out by CIS were greatly welcomed by local people in Romania. Supported by the two universities, for scholarships offered by Hanban, up to present, 109 students majoring in Chinese language from LBUS have benefited from scholarships to renowned universities in China like Beijing Language and Culture University, Fudan University, Peking University, Tsinghua University, Nanjing University etc. Only in 2017, a total of 15 students from LBUS got scholarships offered by Hanban, including 1 postgraduate scholarship, 1 undergraduate scholarship, 1 scholarship for an academic year, 4 government scholarships and 8 scholarships for one semester, in addition to the 12 students having been awarded the Chinese Ambassador Scholarship.

With the tight links of the two universities, CIS is fulfilling the responsibilities of teaching language and promoting Chinese culture efficiently in Romania, helping the learners of Chinese language and fans of Chinese traditions get the chance to know more about China.

\subsection{Links at the local government level: expanding more teaching branches.}

\subsubsection{Linking with the education section of the government at different levels}

Besides the links between two universities at home and abroad, the link between C.I and the local education section is also essential for the sustainable development of C.I., especially under the background of BRI. Effort is made to enhance interregional cooperation in different areas of trade, infrastructure, policy, finance and people in the framework of BRI. The economic development mode of China has set an example among the developing countries along the B\&R. The education section at different levels in Romania have realized the importance of talents who know more about Chinese language and Chinese culture for the future development of the country, starting to open Chinese classes in primary schools, secondary schools and even kindergartens. In 2016, Chinese language has been listed in the credit courses of Ministry of Education in Romania $^{8}$, a great contribution of Bucharest C.I. in promoting the teaching of Chinese language in Romania.

Under the new policy, C.I.S. work hand in hand with the local education department, building up a framework of educating talents interested in Chinese culture. In terms of language teaching, C.I.S has offered two choices to the local education section: A. focusing on language learning in addition to part of cultural activities, a series of HSK exam introduced in the class for a 3-year plan of learning, mainly for the high school students; B. focusing on the interest accumulation of Chinese culture in addition to part of language learning, making the young learners maintain the interest of knowing about China. With the variety of the teaching offer, it turns out easier for the education department at different levels to push forward the Chinese class in targeted schools.

In the past 11 years, CIS continues to consolidate the development of Chinese language and culture teaching in cities like Deva, Pitest, Miercurea Ciuc, Petrosani. We are also try to develop more new teaching branches in the cities like Fagaraș, Camplung, to promote the Chinese course structure of CIS. We have signed cooperation agreements with the local education section of the government to ensure each progress of the work: arranging the class hours of each school, planning for the key culture activities in an academic year, appointing the teachers specifically to the teaching position of all the schools under their control. At the same time, our agreements cover the part concerning CIS providing also opportunities for the local residents to learn Chinese, satisfying the demands for more people in communities. Meanwhile, the link between CIS and education section has enable the increase of the teaching branches.

\subsubsection{The new teaching branches}

Fagaraș: In 2017, a Chinese Class promotion was carried out at Liceul Radu Negru in Fagaraș in Romania. Supported by Nemes Elena, mayor of Fagaraș, and Long Negrila, the teaching director of Brașov. The opening ceremony of the Chinese class was held successfully in the hall of the school. An agreement was signed by CIS and Liceul Radu Negru

\footnotetext{
8 https://www.edu.ro/programe-specifice-pentru-concurs-titularizarecultur $\% \mathrm{C} 4 \% 83$-general $\% \mathrm{C} 4 \% 83$
} 
School for the cooperation in promoting Chinese language and Chinese culture. Liceul Radu Negru is the key school of Braşov, including primary school, junior high school and high school. Chinese language is one of an optional courses in the three levels of schools. The number of students enrolled in the first semester reached 127. Series of cultural activities, for example "Chinese Papercutting", "Happy Children's Day", "Let's paint the panda", were held, having attracted interest of many students in the city.

Camplung: A cultural city located in the north of Argre County. After cooperating with the local government education department, in 2017, all secondary schools around the area began to discuss about Chinese classes, and finally in the new semester of October, the students started their first Chinese class. Up till now, three secondary schools, Dinicu Golescu, Colegiul Pedagogic, Nr. 1 high school, have Chinese classes. The total number of students is about 160 people and the students are beginners of Chinese, so their learning enthusiasm is very high. Students treasure Chinese class once a week a lot, and come to the classroom class early. The hardware of these three schools is well equipped, where Chinese teachers can use multi-media to teach, with visual, auditory, listening way combined to stimulate students interest of learning. Both Success of the Road and HSK Coursebook are used in junior high school students' Chinese classes. Chinese teachers create especially a class form called " $3+1$ ", three is three hours to complete a lesson, one is to carry out cultural experience classes, such as traditional Chinese painting, brush pen introduction and so on. This form has made students learn to write and read while learning about the traditions of Chinese culture.

Iancu Hunedoara: A secondary school with Dan Stefan acts as the headmaster. "Iancu Hunedoara Secondary school" is the best national secondary school in the city. The school is relatively strong in science and engineering. The quality of students is very high. At present, there are 59 new students and four Chinese classes with 4-6 hours a week. On the basis of the cultural department of the school, the Chinese teacher organize the relevant Chinese culture and language activities to expand the influence of Chinese teaching in the city. After one year of Chinese learning, students will participate in HSK1 exam.

In a word, with the support of the education section at different levels, expanding of the branches will become more efficient.

\section{EVALUATION OF THE DEVELOPMENT: CONTROL OF TEACHING QUALITY:}

To maintain the sustainability of development, evaluation will play a part. As far as the principle task of CIS is Chinese teaching and promotion. We can inevitably talk about the source of teacher, especially local teacher, improving teaching quality both in terms of teaching technique and research competence, and making changes to the curriculum of Chinese major in university based on the talents needed under the background of BRI.

\subsection{Sources of local teacher}

The evaluation of development for CIS will bring about the issue of teaching staff. CIS has drawn a blueprint of an ideal multidimensional team of professors and teachers of Chinese language: 2-3 Romanian experts of Chinese in the field of Chinese literature, history, culture and regional research; 2 local lecturers of Chinese language; 5 doctorate students in Chinese major; 5 intern teachers for primary school and secondary schools. Romanian experts, together with 2 visiting scholars from China will be responsible for the lectures for the senior bachelor students, master students and doctorate students, as well as China-Romania international seminars and conference of CIS, leading teachers of CIS in doing research and thesis writing. Furthermore, BRI has provided programs for the Romanian professors to be financially supported to do research in China or inviting Chinese professors abroad to exchange academic research. Local lectures, doctorate students and Hanban teachers will strengthen the basic skills of listening, speaking, reading, writing of the first year and second year students, helping them with application of scholarship to further their study in Chinese universities for either 6 months or 12 months, helping them with their thesis writing, HSK exam and Chinese Bridge Competition. Finally, Hanban volunteer teachers and intern local teachers will be in charge of the primary school and secondary school. The focus here is high school students, leading them to get involved into the activities like Chinese Bridge competition, China Summer Camp, Chinese Spring Festival, and HSK exams.

\subsection{Improving teaching quality}

Teaching quality is the foundation of the sustainable development of Confucius Institute. CIS has been developing for 11 years, having achieved the present 50 teaching branches in 13 cities around the whole country. The enrollment has reached annually 4000 person-time. We are also facing the 
problem of big churn rate of students. In order to maintain sustainable development, improving teaching technique and research competence of the teachers will be essential.

First, CIS has, since the August of 2017, resorted to a new move: new teachers training. The training includes the introduction of cultural differences (culture shock in teaching), the introduction of the teaching points (teaching technique training), management regulations of CIS and model teaching seminar. Second, weekly online teaching regular meeting has been held. We timely communicate about teaching situation and problems in different teaching branches and solve them together through sounds, videos, reports. We will also send experienced teachers to monitor the class and give suggestions if it is necessary. Thirdly, we establish the system of classauditing for the teachers to learn from each other. Finally, we have published our magazine of Confucius, encouraging all teachers to do research and announce their research result either in international conference or in our magazine.

It turns out that some teaching branches are having more students coming to the class and join the Chinese program. The measure of improving the teaching quality turns out to be effective.

\subsection{Curriculum}

Curriculum of Chinese major in university has been revised based on the need of the talents, especially under the background of BRI. BRI leads to more and more investment in countries along the belt and road. Romania is one of the important countries in the list. Therefore, many Chinese companies are coming to open business here, increasing a lot of job positions especially for students speaking both Romanian and Chinese. To make the curriculum more practical, courses like business Chinese have been added in addition to the Chinese culture, history, modern Chinese and literature. The combination with the learning of language and using of language has aroused more interest of Romanian learners of Chinese.

\section{CONCLUSION}

Clearly, what makes "sustainability" possible in Confucius Institute development when facing the challenging as well as opportunities in the international background, especially under the BRI is basically the management support of universities at home and abroad, expanding teaching branches with links between C.I. and education section at different levels makes it possible for C.I. to expand more teaching branches. Finally, teaching quality control is essential for the sustainable development of C.I. The research is based on the qualitative analysis of C.I. at Lucian Blaga University of Sibiu in Romania. With quantitive data analysis of more C.I. in Romanian, the research will be more sufficient and significant. Finally We find that the sustainable development of C.I. can't be realized if any of the above condition we talked about is missed.

\section{BIBLIOGRAPHY}

1. Blum, N. (2012) Education, Community Engagement and Sustainable Development: Negotiating Environmental Knowledge in Monteverde, Costa Rica (Ed.) Dordrecht, Netherlands: Springer

2. Bossel, H. (1999) Indicators for Sustainable Development: Theory, Method, Applications-A Report to the Balaton Group Canada: International Institute for Sustainable Development

3. Filho, W. L. (2011 Ed) World Trends in Education for Sustainable Development Bern, Switzerland: Peter Lang AG

4. Gadsby, H. \& Bullivant, A. (2011 Eds) Global Learning and Sustainable Development London: Taylor \& Francis Ltd

5. Gough, S. \& Scott, W. (2008) Higher Education and Sustainable Development: Paradox and Possibility (Key Issues in Higher Education) London: Taylor \& Francis Ltd

6. Hu, Q.L. (2013) Brief Study on C.I. Sustainable Development in Liberia $[\mathrm{J}]$ Journal of Changchun University of Science and Technology (Social Science Edition) (09): 153-154, 157

7. Jones, P., Selby, D. \& Sterling, S. (2010 Eds) Sustainability Education-High Education London: Earthscan

8. Nikolopoulou, A. (2010) Education for Sustainable Development: Challenges, Strategies and Practices in a Globalizing World

9. Sun, J. (2012) Study on Strategy of Sustainable Development of Russian C.I.[J] Course Education Research (29):9

10. Wang, J. (2011) Strategy and Resolution for Sustainable Development of C.I. [J] Journal of Weifang Educational College, 24(06): 31-33

11. Xu, F.H. (2015) Carry forward the Spirit of the Silk Road and Start a New Chapter of Cooperation retrieved from http://www.fmprc.gov.cn/ce/cgvienna/chn/zt/ydyl/t1239213.htm

12. Zhan, Ch.Y.\& Li, M.N. (2014) Sustainable Development of C.I.: Indicator, Mode and Prospect [J] Journal of South China Normal University (Social Science Edition) (5): 78-82 